Polymer Journal, Vol. 4, No. 2, pp 115-119 (1973)

\title{
Molecular Motion in Amorphous Polyurethane
}

\author{
Masanobu NAGURA and Eiichi WADA \\ Department of Engineering Chemistry, College of Science and Technology \\ Nihon University, Kanda, Tokyo, Japan.
}

(Received December 6, 1971)

\begin{abstract}
The dependence of the molecular motion of polyurethane on the length of methylene chain in the monomer unit and on the molecular weight has been studied by the broad line nuclear magnetic resonance, NMR, dynamic loss modulus, $E^{\prime \prime}$, wide angle X-ray scattering, and the density.

The second moment, $\left\langle\Delta H^{2}\right\rangle$, at the rigid state increases with an increasing number of methylene groups.

The degree of narrowing of $\left\langle\Delta H^{2}\right\rangle$ for the secondary dispersion increases with increasing numbers of methylene groups. This agrees with the theoretical prediction based on the local mode motion of the main chain. The force constant of the local mode motion of the polymethylene chain thus estimated is $3.0 \times 10^{-13} \mathrm{erg}$. The dispersion of the dynamic loss modulus at about $-135^{\circ} \mathrm{C}$ corresponds to the above secondary dispersion of $\left\langle\Delta H^{2}\right\rangle$.

The primary dispersion temperature decreases with decreasing molecular weight.

KEY WORDS Molecular Motion / Amorphous Polyurethane / Broad-

Line NMR / Dynanic Loss Modulus / Wide-Angle X-ray Scattering /

Density / Force Constant / Polymethylene Chain /
\end{abstract}

Jacobs and Jenckel ${ }^{1}$ have studied the effects of the number of methylene groups in the monomer unit and crystallinity on the molecular motion of crystalline polyurethane,

$\left.+\mathrm{COO}\left(\mathrm{CH}_{2}\right)_{m} \mathrm{OOCNH}\left(\mathrm{CH}_{2}\right)_{6} \mathrm{NH}\right\}_{p}$, by dynamic mechanical measurements.

Shibata $^{2}$ has studied the molecular motion of the above sample of a low degree of cystallinity by the broad-line NMR, and pointed out that the high value of the second moment, $\left\langle\Delta H^{2}\right\rangle$, near the melting point can be attributed to the hydrogen bonds of urethane groups in the amorphous part.

In previous papers ${ }^{3,4}$, some preliminary results were reported on the molecular motion of polyurethane. In this paper, the dependence of the molecular motion of amorphous polyurethane, ${ }_{-}-\mathrm{NH}\left\langle\mathrm{CH}_{2}\left\langle>\mathrm{NHCOO}\left(\mathrm{CH}_{2}\right)_{n} \mathrm{OOC}\right\}_{p}\right.$, on the length of methylene chain in the monomer unit and on the molecular weight have been studied by the broad line NMR, the dynamic loss modulus, the wide angle $\mathrm{X}$-ray scattering and the density.

\section{EXPERIMENTAL}

Four samples of polyurethane $+\mathrm{NH}$. $\mathrm{CH}_{2}\left\langle\mathrm{NHCOO}\left(\mathrm{CH}_{2}\right)_{n} \mathrm{OOC}\right\}_{p}, n=2,4,5$ and 9 were prepared by polycondensation ${ }^{5}$ of methylene bisphenyl-isocyanate(MDI) with ethylene glycol(EG), butylene glycol(BG), pentamethylene glycol(PG) and nonamethylene glycol(NG). The structural formulas of these samples are shown in Table I. The polyurethane polymers were dissolved in dimethylformamide at $100^{\circ} \mathrm{C}$ and poured into ice water. The wide angle $\mathrm{X}$-ray scattering patterns of the samples show only an amorphous halo (Figure 1).

The sample powder dried in vacuum at $70^{\circ} \mathrm{C}$ was sealed into a glass tube, and the tube was placed in the sample holder of the broad-line NMR spectrometer. The NMR apparatus used is a commercial model (Nippon Denshi Kogyo Co., Ltd., Tokyo) equipped with autodyne detector and an electromagnet of homogeneous, constant magnetic field. The first derivatives of the NMR adsorption signal were recorded at a magnetic field corresponding to $25 \mathrm{MHz}$. The 
M. NAGURA and E. WADA

Table I.

\begin{tabular}{|c|c|c|}
\hline Structural formula of the sample & $R$-value & $\bar{M}_{n}$ \\
\hline \multicolumn{3}{|l|}{ EG-MDI } \\
\hline$\left.>\mathrm{NHCOO}\left(\mathrm{CH}_{2}\right)_{2} \mathrm{OOC}\right\} p$ & 1.0 & - \\
\hline \multicolumn{3}{|l|}{$\mathrm{EG}-\mathrm{MDI}$} \\
\hline $\mathrm{NHCOO}\left(\mathrm{CH}_{2}\right)_{4} \mathrm{OOC}+p$ & 1.0 & - \\
\hline \multicolumn{3}{|l|}{$\mathrm{PG}-\mathrm{MDI}$} \\
\hline $\mathrm{HCOO}\left(\mathrm{CH}_{2}\right)_{5} \mathrm{OOC}+$ & $\begin{array}{l}1.0 \\
0.6\end{array}$ & $\begin{array}{l}4600 \\
1400\end{array}$ \\
\hline \multicolumn{3}{|l|}{ NG-MDI } \\
\hline $\left.\mathrm{NHCOO}\left(\mathrm{CH}_{2}\right)_{9} \mathrm{OOC}\right\} p$ & 0.664 & - \\
\hline
\end{tabular}

a Ratio of the number of isocyanate to that of hydroxyl group used for the synthesis.

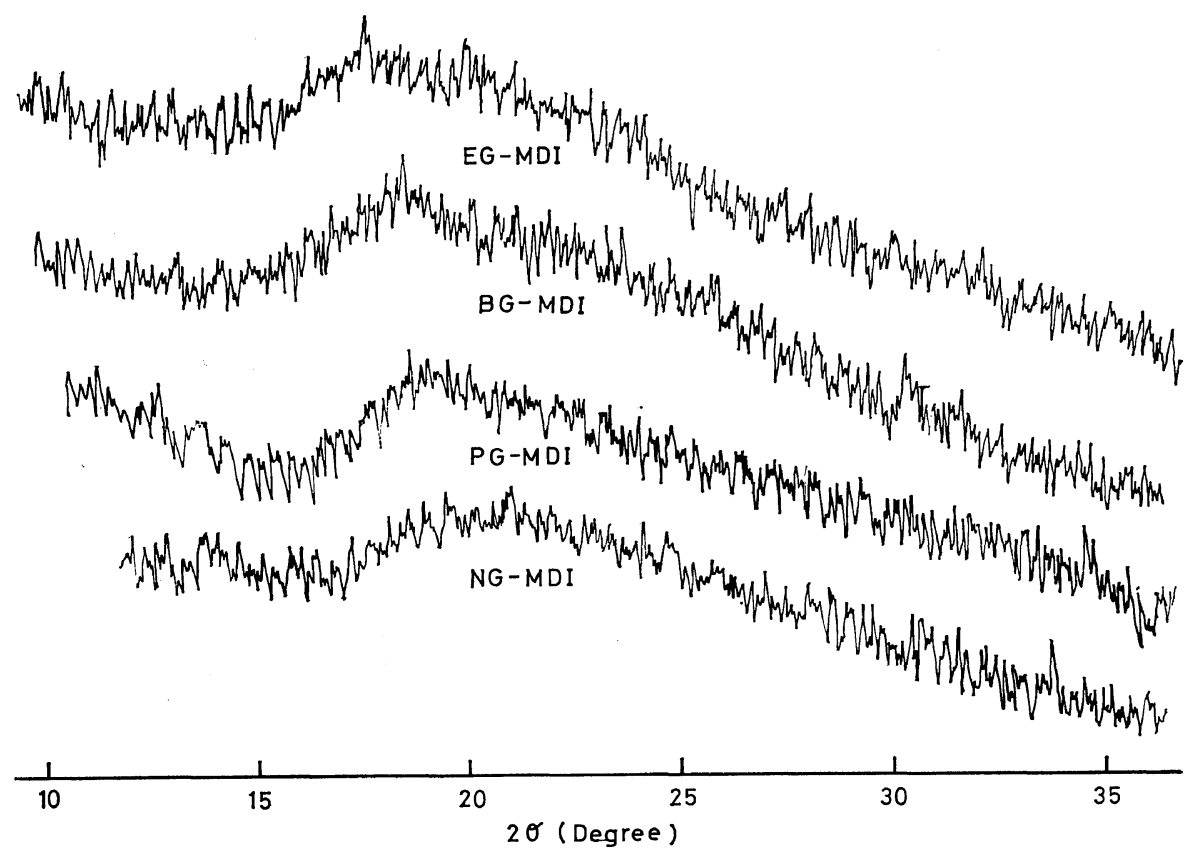

Figure 1. $\mathrm{X}$-ray patterns for $\mathrm{EG}-\mathrm{MDI}, \mathrm{BG}-\mathrm{MDI}, \mathrm{PG}-\mathrm{MDI}$ and $\mathrm{NG}-\mathrm{MDI}$.

temperature was controlled by a heating coil in air, liquid $\mathrm{N}_{2}$ or a Dry Ice-acetone mixtre in Dewar vessel.

The dynamic loss modulus, $E^{\prime \prime}$, was measured with a forced stretching vibration ${ }^{6}$ by $10 \mathrm{~Hz}$ from liquid $\mathrm{N}_{2}$ temperature up to about $100^{\circ} \mathrm{C}$. The samples were heat pressed, quenched in ice water and cut into strips $(20 \times 1 \times 1.5 \mathrm{~mm})$.

The wide angle $\mathrm{X}$-ray scattering was measured with Debye-Sherrer camera using Ni-filtered
$\mathrm{Cu}-\mathrm{K}_{\alpha}$ radiation.

The density was measured by the flotation method in the mixture of $n$-heptane and carbon tetrachloride at $15^{\circ} \mathrm{C}$.

\section{RESULTS AND DISCUSSION}

Figure 2 shows the first derivatives of the NMR adsorption signal for PG-MDI. Every line shows only one component, which suggests that 


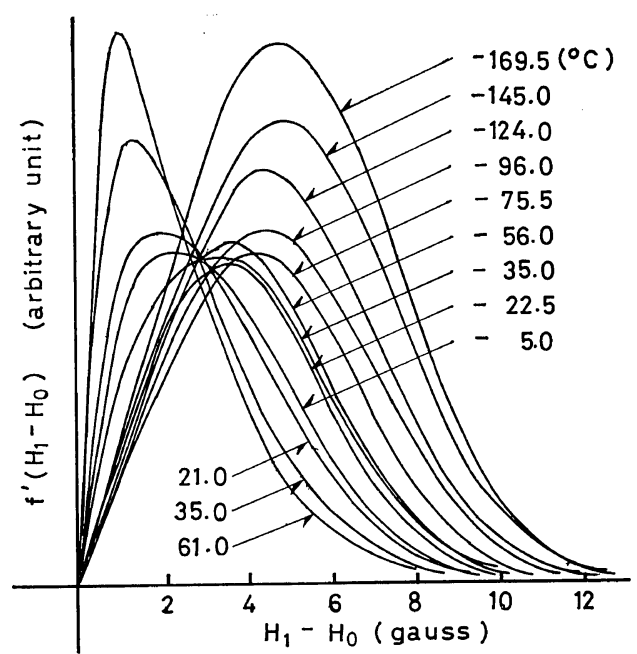

Figure 2. Halves of the first derivatives of the NMR adsorption signal for $\mathrm{PG}-\mathrm{MDI}$ : $\mathrm{H}_{1}$, radio frequency magnetic field; $H_{0}$, main magnetic field.

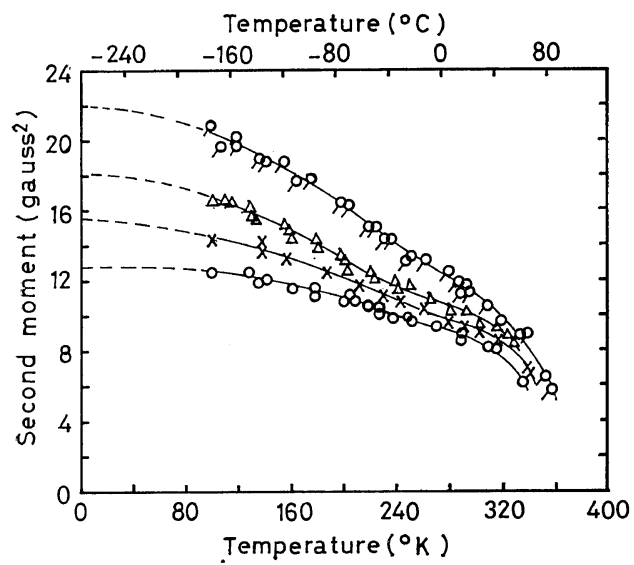

Figure 3. Temperature dependence of the second moment for polyurethane: $\bigcirc, \mathrm{EG}-\mathrm{MDI} ; \times$, BG-MDI; $\triangle$, PG-MDI; $\rho$, NG-MDI.

sample has no crystalline region.

Figure 3 shows the plots of the $\left\langle\Delta H^{2}\right\rangle$ against temperature for EG-MDI, BG-MDI, PGMDI and NG-MDI. The narrowing corresponding to the secondary dispersion of the $\left\langle\Delta H^{2}\right\rangle$ is observed at $-30^{\circ} \mathrm{C}$ beside the primary one which is seen above $50^{\circ} \mathrm{C}$ and the degree of the narrowing increases with increasing number of methylene groups. The $\left\langle\Delta H^{2}\right\rangle$ at the secondary dispersion temperature region increases with increasing number of methylene group. The observed $\left\langle\Delta H^{2}\right\rangle$ is obtained as the sum of the intermolecular $\left\langle\Delta H^{2}\right\rangle$ and the intramoleular $\left\langle\Delta H^{2}\right\rangle$. In this case, since the density decreases with increasing number of methylene groups as shown in Figure 4, it is reasonable to consider that the intermolecular $\left\langle\Delta H^{2}\right\rangle$ decreases as the number of methylene groups increase. While the intramolecular $\left\langle\Delta H^{2}\right\rangle$ increases generally with increasing number of methylene groups in which the interproton distance is the shortest for a polymer molecule. Therefore, the above result may be explained by the increase of the intramolecular $\left\langle\Delta H^{2}\right\rangle$ rather than by the decrease of the intermolecular $\left\langle\Delta H^{2}\right\rangle$.

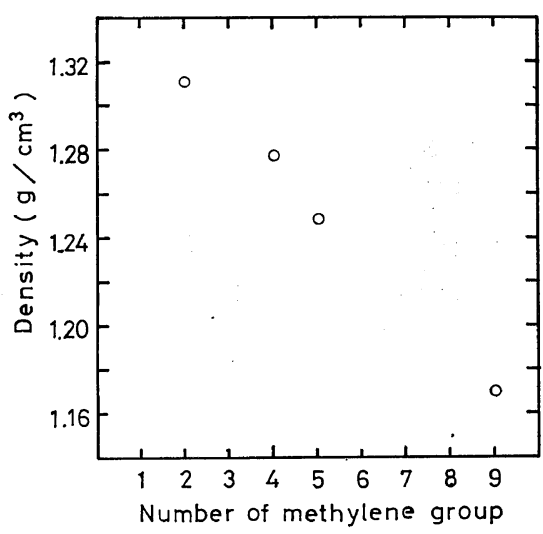

Figure 4. Plot of the density vs. the number of methylene group in the structural unit of polyurethane.

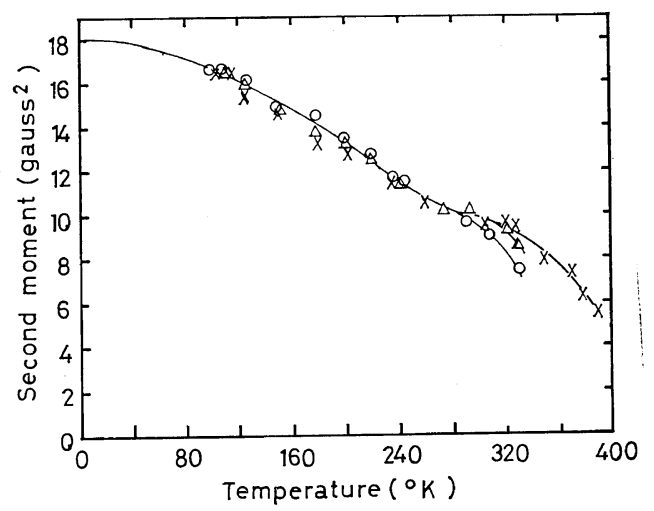

Figure 5. Molecular weight dependence of the second moment for PG-MDI: $\times, \bar{M}_{n}=4600 ; \triangle$, $\bar{M}_{n}=1400 ; \bigcirc, \bar{M}_{n}=980$. 
As shown in Figure 5, three plots for PGMDI having different $R$-values fall on single curve in the secondary narrowing reaction, where $R$-value means the ratio of the number of diisocyanate groups to that of hydroxyl groups used for the synthesis. The molecular weight increases with increasing $R$-value as shown in Table I. Therefore, when the monomer unit has a soft segment such as $-\mathrm{O}\left(\mathrm{CH}_{2}\right)_{n} \mathrm{O}-$, the secondary narrowing appears independent of the molecular weight. Dependence of the narrowing on the length of the methylene chain in the monomer unit is clearly seen in Figure 6, which is a replot

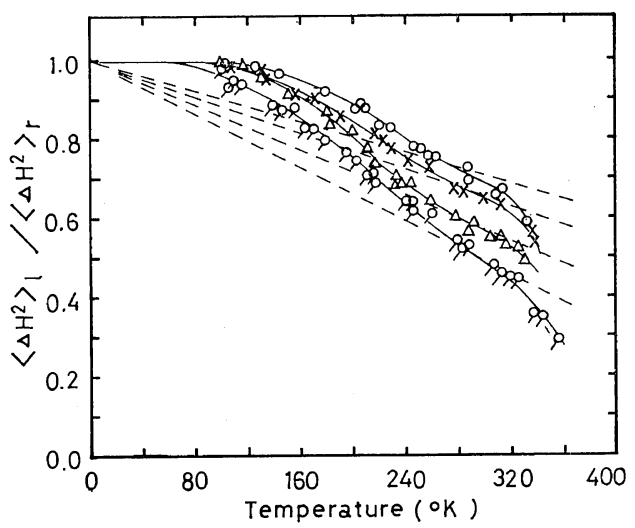

Figure 6. Plots of $\left\langle\Delta H^{2}\right\rangle_{1}\left\langle\Delta-H^{2}\right\rangle_{\mathrm{r}} v s$. temperature for polyurethane; $\bigcirc, \mathrm{EG}-\mathrm{MDI} ; \times, \mathrm{BG}-\mathrm{MDI}$; $\triangle, \mathrm{PG}-\mathrm{MDI} ; \rho, \mathrm{NG}-\mathrm{MDI}$.

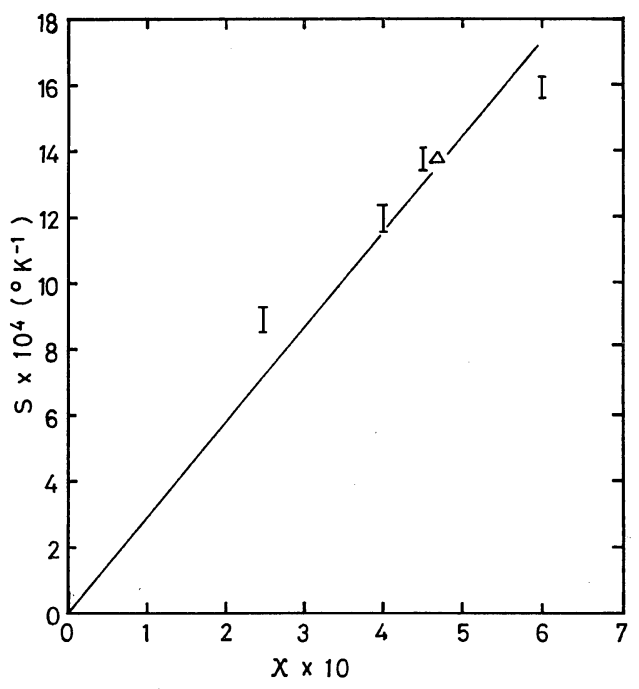

Figure 7. Plot of $S$ vs. $X$. of Figure 3. In the figure, $\left\langle\Delta H^{2}\right\rangle_{1}$ and $\left\langle\Delta H^{2}\right\rangle_{\mathrm{r}}$ denote the second moments at the temperature where the secondary dispersion appears and that at the rigid state, respectively. Figure 7 shows the plot of the slopes of the dotted lines in Figure 6 against $X$, which is the ratio of the number of protons in the methylene group in the soft segment, e.g., $-\mathrm{O}\left(\mathrm{CH}_{2}\right)_{n} \mathrm{O}_{-}$, to that of all protons in the monomer unit of the polyurethane molecule. As shown in Figure $7, S$ is almost proportional to $X$. This result agrees with the following theoretical consideration based on the assumption that the secondary dispersion is mainly caused by the local mode motion of the methylene groups?

$$
\begin{aligned}
\frac{\left\langle\Delta H^{2}\right\rangle_{1}}{\left\langle\Delta H^{2}\right\rangle_{\mathrm{r}}} & =1-S T \\
S & =\frac{6 k X}{\sqrt{4 f_{1} g_{1}}}
\end{aligned}
$$

For eq $2 f_{1}$ and $g_{1}$ are the intra and intermolecular force constants, $T$ the absolute temperature and $k$ Boltzmann's constant. The force constant of local mode motion, $\sqrt{4 f_{1} g_{1}}$, of polyurethane calculated from the slope of solid line in Figure 6 is about $3.0 \times 10^{-13}$ erg. The force constant of polyethylene estimated by Okano $^{7}$ is about $1.3 \times 10^{-13} \mathrm{erg}$. The larger value for polyruethane may be due to the effects of the inter and intramolecular hydrogen bonding. This may be supported by the observation made for Nylon- $66^{8}$, which has $\mathrm{NH}$ groups in the monomer unit; the value of $S$ for Nylon-66 is shown by a triangle in the same fiigure and it falls on the line for polyurethane.

Figure 8 shows the temperature dependence of the dynamic loss modulus, $E^{\prime \prime}$, for BG-MDI and $\mathrm{PG}-\mathrm{MDI}$ at $10 \mathrm{~Hz}$. By using an activation energy of $10 \mathrm{kcal} / \mathrm{mol}$, which is obtained for the local mode motion of polymethylene chain calculated from the slope of the dispersion map of the polyamide ${ }^{9}$, the temperature at which the secondary dispersion appears in the $E^{\prime \prime}$ for $\mathrm{BG}-\mathrm{MDI}$ and $\mathrm{PG}-\mathrm{MDI}$ is predicted as $-125^{\circ} \mathrm{C}$. As shown in the figure, the dispersion appears at $-135^{\circ} \mathrm{C}$ which is very close to the above predicted temperature. Therefore, it is very likely that the dispersion at $-135^{\circ} \mathrm{C}$ corresponds to the local mode motion. According to Dammont and $\mathrm{Kwei}^{10}$, a dispersion at low temperature 
Molecular Motion in Amorphous Polyurethane

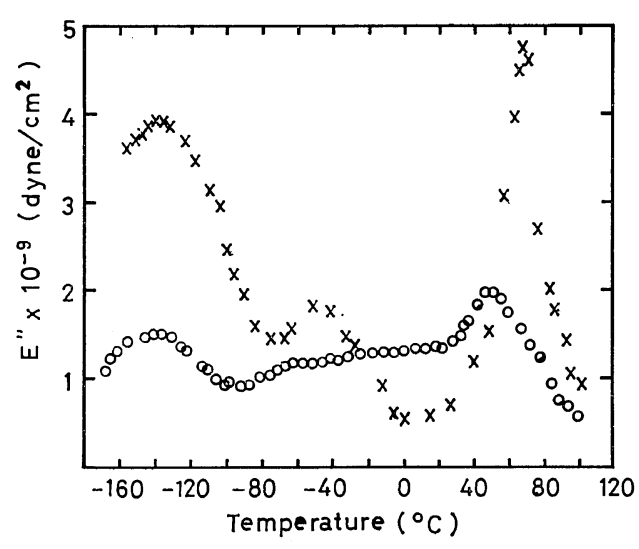

Figure 8. Temperature dependence of the dynamic loss modulus, $E^{\prime \prime}$, for polyurethane: $\bigcirc, \mathrm{BG}-$ MDI; $\times$, PG-MDI.

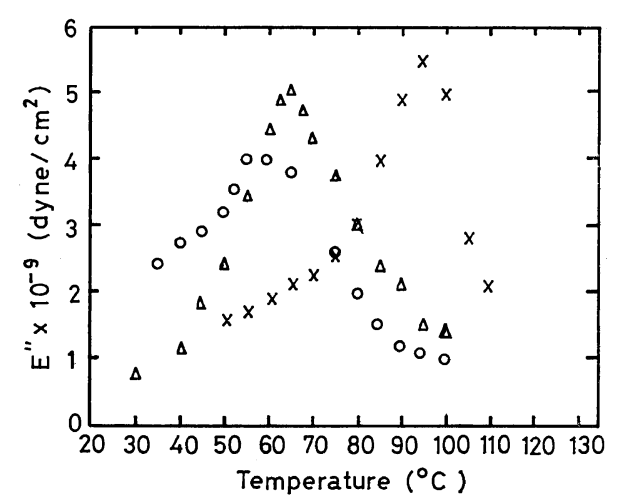

Figure 9. Molecular weight dependence of the dynamic loss modulus, $E^{\prime \prime}$, for PG-MDI: $\times$, $\bar{M}_{n}=4600 ; \triangle, \bar{M}_{n}=1400 ; \bigcirc, \bar{M}_{n}=980$.

was observed for Epoxy resin cured with diamine having more than four methylene groups. Shatzki ${ }^{11}$ has attributed it to the crank-shaft motion among the four methylene groups. In the present samples, the secondary dispersion of the $\left\langle\Delta H^{2}\right\rangle$, however, was observed even for the sample having two methyjene groups in the monomer unit. This may be attributed to the fact that the monomer unit contains $-\mathrm{C}-\mathrm{O}-\mathrm{C}-$ bond, which is more flexible than $-\mathrm{C}-\mathrm{C}-$ bond.

The dispersion at $-50^{\circ} \mathrm{C}$ is due to the adsorption of water because it disappeared in the sample dried in vacuo for six days, and that at $60^{\circ} \mathrm{C}$ is the primary one corresponding to motional narrowing at about $70^{\circ} \mathrm{C}$ in Figure 3 . Figure 9 shows the dependence of the primary dispersion temperature on the molecular weight. It is evident that the dispersion temperature decreases with decreasing molecular weight, and that each temperature corresponds to the primary narrowing temperature of the $\left\langle\Delta H^{2}\right\rangle$ (Figure 5).

Acknowledgment. The authors wish to express their heartfelt thanks to Dr. K. Okano of the University of Tokyo and Dr. M. Hideshima of Hokkaido University for their valuable discussion and also to Mr. N. Ishikawa for his preliminary measurements.

\section{REFERENCES}

1. H. Jacobs and E. Jenkel, Maromol. Chem., 43, 132 (1961).

2. T. Shibata, K. Hikichi, and M. Kaneko, Rep. Progr. Polym. Phys. Japan, 11, 393 (1968).

3. E. Wada, N. Ishikawa, M. Hideshima, M. Kakizaki, and K. Okano, ibid., 10, 389 (1967).

4. E. Wada, M. Nagura, H. Tagawa, and K. Kanamaru, ibid., 11, 342 (1968).

5. D. J. Lyman, J. Polym. Sci., 45, 49 (1960).

6. E. Fukada and M. Date, Japan J. Appl. Phys., 1, 59 (1962).

7. K. Okano, Rep. Institute Phys. Chem. Res., 40, 273 (1964).

8. A. E. Woodward, J. Polym. Sci., 45, 367 (1960).

9. Y. Wada, J. Phys. Soc. Japan, 16, 1226 (1960).

10. F. R. Dammont and T.K. Kwei, J. Polym. Sci., Part A-2, 5, 761 (1967).

11. T. F. Shatzki, ibid., Part C, 14, 139 (1966). 